\title{
Fronteira Brasil - Bolívia em Mato Grosso: segurança pública, desenvolvimento social e a construção da identidade nacional
}

\author{
Brazil - Bolivia border in Mato Grosso: \\ public security, social development \\ and the construction national identity
}

Rev. Bras. Est. Def. v. 4, nº 2, jul./dez. 2017, p. 219-239

\section{DANIEL ALMEIDA DE MACEDO}

\section{INTRODUÇÃO}

Em regiões de fronteira a interação entre os países limítrofes é uma realidade diária que compreende fluxos de pessoas, comércio de mercadorias, transações financeiras e intercâmbio cultural. Em seu conjunto, essas práticas podem significar um fator de desenvolvimento e contribuir de forma positiva para o progresso e bem-estar das populações envolvidas. Não obstante, a fragilidade das políticas destinadas a garantir o controle e a segurança pública nas regiões brasileiras de fronteira torna as economias e as mobilidades fronteiriças vulneráveis à ação nefasta do crime organizado, que se materializa na cooptação para o tráfico de drogas, de pessoas, de armas, no contrabando e na lavagem de dinheiro. De forma sintética, o objetivo deste texto é realizar um exercício analítico da região de fronteira Brasil - Bolívia em Mato Grosso, buscando descobrir como atores, dinâmicas e políticas em diferentes escalas (estadual e federal) se articulam neste espaço e atuam enfrentando os problemas relativos à segurança para alcançar o desenvolvimento social.

Em razão de sua importância estratégica e geopolítica, as regiões de fronteira são áreas de preocupação central para a defesa e segurança nacional. São o ponto de encontro entre nações, e, portanto, parte sensível do território pátrio, o que exige um enquadramento especial dentro das políticas definidas para a salvaguarda da sociedade e proteção do Estado.

Daniel Almeida de Macedo - Programa de Pós-Graduação em História da Universidade Federal de Mato Grosso - PPGHIS/UFMT. 
É nesses espaços que se delimita o exercício da autoridade soberana, isto é, no ponto preciso em que o poder de império nacional chega ao seu fim é que se encontram as fronteiras.

Nos Estados Unidos o maior nome da teoria das fronteiras foi Frederick Jackson Turner (1861-1932). A tese da fronteira, apresentada por Turner em 1893 na obra The significance of the frontier in American History, teve grande influência na historiografia brasileira do século XX. Sérgio Buarque de Holanda, influenciado pela tese da fronteira desenvolvida por Turner, reforça a pertinência e aplicabilidade dos conceitos de safety valve (válvula de segurança) para as fronteiras brasileiras. Para Buarque de Holanda, essas válvulas de segurança teriam "o papel de desafogar os centros mais industrializados, evitando assim o acirramento de conflitos sociais e econômicos" (Wegner 2000,99).

Golbery do Couto e Silva, um dos principais teóricos da doutrina de segurança nacional, elaborada nos anos 1950 pelos militares brasileiros da Escola Superior de Guerra (ESG), considerava que as regiões de fronteira do Centro-Oeste representavam zonas de vulnerabilidade máxima. Golbery, que desempenhou a função de articulista cardeal do governo militar, propugnava a "integração desses desertos ao núcleo central ecumênico como forma de se reforçar a estrutura econômica nacional e mitigar as ameaças de ataques solertes" (Silva 1967, 126).

No Brasil, as zonas de fronteira têm sido historicamente avaliadas pelas autoridades nacionais, e também por historiadores e geógrafos, como espaços periféricos que têm a função de áreas-tampão $o^{1}$ em relação ao restante do continente. Essa abordagem tem levado as áreas de fronteira a serem consideradas precipuamente a partir do enfoque da defesa e segurança (Fagundes; Rückert 2014, 1). Essa moldura conceitual, sobre a qual se convencionou fixar as fronteiras brasileiras, no entanto, já não parece ser adequada ou ampla o suficiente para abranger a complexa realidade desses lugares que se caracterizam por apresentar uma natureza multifacetada. Ao mesmo tempo em que são regiões que inspiram forte preocupação com questões relacionadas à segurança, proteção e soberania, as fronteiras no Brasil do século XXI transcendem tais aspectos. São áreas definidas também por compreender estruturas produtivas específicas, que apresentam intensa diversidade econômica, social e cultural, e, ainda, são regiões que abrigam ecossistemas com admirável biodiversidade. Assim, é indispensável considerar aspectos de segurança e defesa em regiões de fronteira, mas também é importante ir além dessas significações e alcançar outras categorias de análise. A representação das fronteiras como espaços plenos de oportunidades em contraposição à ideia de espaços-problema é uma construção narrativa que pode atrair e favorecer o desenvolvimento, pois sinaliza 
possibilidades em espaços tradicionalmente associadas ao crime e à periculosidade. Sem desconsiderar os imperativos de segurança nacional, mas sim o oposto, considerando-os verdadeiros vetores para o desenvolvimento social, é primordial debater de maneira abrangente os desafios e oportunidades associados às regiões limítrofes do território nacional. Sobretudo, é importante entender esses espaços como regiões com possibilidades exclusivas de desenvolvimento e capazes de promover o crescimento econômico sub-regional, pois são áreas de fluxo onde ocorre a interação entre mercados binacionais. Por outro lado, regiões de fronteira também são áreas de sensível importância para a integridade nacional, já que nessas parcelas do território a existência de um sentido patriótico entre os cidadãos significa um importante fator para manutenção da unidade nacional.

Nesse contexto plurifacetado que caracteriza as fronteiras brasileiras, ao Poder Público incumbiria o dever de fortalecer as instituições públicas locais e impulsionar o progresso intensificando as vantagens comparativas da região. Essas ações resultam no fortalecimento do sentimento cívico do qual derivam os valores de uma sociedade, isto é, a consciência das responsabilidades e dos deveres do cidadão. Assim, melhorar a infraestrutura local e criar formas de acesso a linhas de financiamento para produtores locais são, por exemplo, iniciativas promissoras que impulsionam o progresso e, indiretamente, fortalecem a consciência cívica. É igualmente importante atacar os problemas crônicos que afetam as comunidades de fronteira, ou seja, "a falta de alternativas de emprego, educação, lazer, falta de regularização e excessiva concentração da terra” (Neves 2016, 69). Funcionando dessa forma, o Estado alicerça nas sociedades fronteiriças a ideia de pertencimento a uma comunidade política imaginada, ${ }^{2}$ um conceito essencial ao sentimento de nacionalismo e identificação com uma nação.

Uma expressão das oportunidades econômicas que a região de fronteira reserva é a pecuária extensiva. Dez municípios de Mato Grosso figuram entre os 40 maiores produtores de gado do Brasil. A cidade fronteiriça de Cáceres (MT) possui o $4^{\circ}$ maior rebanho nacional, com 1,024 milhão de cabeças, ficando atrás apenas de São Félix do Xingu (PA), Corumbá (MS) e Ribas do Rio Pardo (MS), segundo relatório divulgado pela Associação Brasileira das Indústrias Exportadoras de Carne (ABIEC 2016). A pesquisa mostra um crescimento de 130,89\% no comparativo com 1994, quando o município possuía apenas 443,5 mil cabeças. Os números fazem parte do Perfil da Pecuária no Brasil - Relatório Anual, desenvolvido em conjunto com a Agência Brasileira de Promoção de Exportações e Investimentos (Apex-Brasil) no projeto intitulado Brazilian Beef. ${ }^{3}$

Com efeito, a multifacetada realidade da região da fronteira Brasil - Bolívia em Mato Grosso, na qual convivem agentes econômicos, co- 
munidades locais, grupos transnacionais e os governos federal, estadual e municipal, resulta em um ambiente cuja compreensão demanda uma abordagem que perpassa aspectos exclusivamente policiais ou militares. Buscando encontrar uma forma de se compreender como atores, dinâmicas e políticas em diferentes dimensões se articulam nesse espaço, optou-se nesse texto por utilizar como método de procedimento as escalas geográficas (Racine; Raffestin 1983). Os recortes analíticos utilizados na geografia humana são o lugar (cidade ou bairro), a região, a nação e o mundo. Esse arranjo tem como propósito descobrir as relações existentes entre as escalas, conforme a literatura especializada (Castro 1995). Para fins de análise do espaço geográfico objeto deste estudo são consideradas somente a escala nacional e a escala estadual. Na escala nacional são analisadas as políticas e ações do Estado brasileiro para a gestão da segurança, defesa dos territórios fronteiriços e desenvolvimento regional. Na escala local, que corresponde à região da fronteira Brasil - Bolívia em Mato Grosso, o objetivo é identificar e descrever as políticas da unidade federativa para o lugar, e como essas políticas se articulam com as iniciativas da União. Cumpre esclarecer que neste estudo específico não foi elaborado um segmento sobre a escala global.

\section{ESCALA NACIONAL: PLANOS E OPERAÇÕES DE SEGURANÇA E DEFESA NACIONAL}

O Brasil faz fronteira com 10 países da América do Sul. São mais de $15 \mathrm{mil} \mathrm{km} \mathrm{de} \mathrm{divisa} \mathrm{terrestre.} \mathrm{Na} \mathrm{faixa} \mathrm{de} \mathrm{fronteira,} \mathrm{isto} \mathrm{é,} \mathrm{a} \mathrm{distância} \mathrm{de}$ 150 quilômetros a partir desta divisa, há aproximadamente 570 municípios brasileiros distribuídos em $27 \%$ do território nacional, onde residem cerca de dez milhões de brasileiros (Brasil 2016a). A Lei $n^{\circ} 6.634$, de 2 de maio de 1979, dispõe sobre a faixa de fronteira, cujo regulamento está disposto no Decreto $\mathrm{n}^{\circ} 85.064 / 80$. A mencionada lei não proíbe atividades e não veda atuação de estrangeiros ou pessoas jurídicas estrangeiras na faixa de fronteira, mas estabelece procedimentos a serem seguidos para a prática de atos que necessitem de assentimento prévio do Conselho Nacional de Defesa (CND)

Um dos fatores que torna a vida na fronteira uma realidade difícil para seus habitantes no Brasil é a distância das capitais e de outros grandes centros urbanos, onde os serviços básicos disponíveis à população são geralmente melhores e ofertados de maneira mais abrangente, como é o caso da educação e da assistência hospitalar. A situação de desamparo de grande parte da população fronteiriça inibe, em grande medida, o exercício dos direitos fundamentais e as torna vulneráveis à ação de organizações pa- 
ralelas que se constituem e desenvolvem na ausência do poder formal do Estado.

Por meio dessa fissura na rede de proteção e assistência social, especialmente em situações geradoras de necessidades, as atividades ilícitas se inserem e corrompem as relações sociais de produção, as práticas comerciais e o uso da propriedade. Em outras palavras, a situação de abandono pelo Estado torna as populações locais mais suscetíveis a atividades ilícitas ou degradantes, como é o caso do narcotráfico e da prostituição. A esse cenário de vulnerabilidade social acrescenta-se os obstáculos operacionais tão característicos das regiões remotas de fronteira, isto é, as distâncias, as vias de deslocamento precárias, a dificuldade/impossibilidade de comunicação, terrenos com florestas, rios e morros, etc., que tornam o patrulhamento e as intervenções policiais tardias. Esse conjunto de fatores propicia que a área seja abundante em atividades ilícitas, conforme explica o policial militar Paulo Meneses sobre a fronteira em Mato Grosso:

[...] é cortada por centenas de vias vicinais clandestinas, com distâncias consideráveis a serem percorridas, cujos relevos apresentam uma grande diversidade de formas, onde estão inseridos três ecossistemas (floresta amazônica, cerrado e pantanal), características peculiares que tornam a região um cenário muito desgastante para operadores de segurança e seus meios (Meneses 2010, 215).

A realidade de ilicitudes que se propaga nas fronteiras do Brasil alterou a orientação do planejamento estratégico tradicionalmente concebido para essas porções do país. Segundo Adriana Dorfman (2013), as fronteiras brasileiras já não despontam atualmente como uma questão de segurança nacional, mas, sobretudo, de segurança pública. Para a geógrafa, predomina a percepção de que as fronteiras terrestres do Brasil correspondem a uma zona periférica problemática de ilícitos transnacionais que trazem problemas de segurança pública para as regiões próximas ao litoral. Essa interpretação é compartilhada por José Mariano Beltrame, ex-secretário de segurança do Estado do Rio de Janeiro. A propósito das operações militares-policiais que expulsaram traficantes que aterrorizavam e dominavam a região do morro do Alemão em 2010, Beltrame afirmou:

Tudo o que vocês viram na imprensa hoje - as armas, as drogas -, nada daquilo é produzido no Rio. Basicamente, entram pelo Paraguai e pela Bolívia. Temos problemas sérios com relação à dimensão da nossa fronteira. São 16 mil quilômetros de fronteira seca. Não vai nenhuma crítica aqui a nenhuma instituição. $\mathrm{O}$ que eu acho é que a sociedade deve cobrar que deem condições para a Polícia Federal, Polícia Rodoviária Federal, Receita Federal, ou seja lá quem for, para cobrir essas fronteiras. Porque, senão, daqui a pouco as coisas come- 
çam a acontecer novamente. Espero que a sociedade cobre soluções rápidas para isso (Beltrame, 2010).

Sem embargo das oportunidades econômicas reais ou potenciais, regiões de fronteira são efetivamente extensões territoriais onde se faz indispensável a atuação de forças de segurança pública e defesa nacional. As chances de desenvolvimento econômico-social restariam definitivamente bloqueadas caso não fossem executadas políticas de fiscalização e repressão dos delitos transfronteiriços e outros delitos praticados na faixa de fronteira.

Ao longo da linha divisória entre o Brasil e a Bolívia em Mato Grosso, convergem em um mesmo espaço físico políticas públicas de segurança das esferas estadual e federal. No plano federal, é aplicada a Estratégia Nacional de Segurança Pública nas Fronteiras (Enafron), um programa no âmbito da Secretaria Nacional de Segurança Pública (Senasp) do Ministério da Justiça, concebida com o propósito de garantir a segurança nas fronteiras do país (Brasil 2016a). Já no âmbito estadual, a principal ação de segurança destinada à região de fronteira com a Bolívia é desempenhada pelo Grupo Especial de Segurança da Fronteira (Gefron) criado no Estado de Mato Grosso, no dia 13 de março de 2002, por meio do Decreto Estadual $n^{\circ}$ 3.994. São ações convergentes em seus objetivos, mas diferentes em seus métodos. A Enafron é um conjunto de políticas e projetos do governo federal vigorosamente estruturada na articulação interagências, no planejamento estratégico das ações e no eventual financiamento de estruturas e aquisição de meios para a execução de operações de segurança na fronteira. O Gefron por sua vez, atua como um pelotão especial de fronteira, isto é, realiza operações sistemáticas de prevenção e repressão ao tráfico de drogas, contrabando e descaminho de bens e valores, roubo e furto de veículos e invasões de propriedades (Neves 2016).

A crescente preocupação com a vulnerabilidade das zonas de fronteira no Brasil impulsionou a elaboração de uma agenda de segurança e defesa que define políticas que visam à gestão territorial desses espaços. Em 17 de novembro de 2016 foi instituído o Programa de Proteção Integrada de Fronteiras (PPIF), para o fortalecimento da prevenção, do controle, da fiscalização e da repressão aos delitos transfronteiriços. O objetivo maior do PPIF é integrar e articular ações de segurança pública da União, de inteligência, de controle aduaneiro e das Forças Armadas com as ações dos estados e municípios situados na faixa de fronteira. Segundo o Decreto Federal $n^{\circ}$ 8.903, de 16 de novembro de 2016, que cria o PPIF, entre as medidas a serem promovidas está o compartilhamento de informações e ferramentas e a implementação de projetos estruturantes, visando o for- 
talecimento do Estado brasileiro nas fronteiras. O novo órgão será integrado por representantes do Gabinete de Segurança Institucional da Presidência da República, da Agência Brasileira de Inteligência (Abin), do Estado-Maior Conjunto das Forças Armadas, da Secretaria da Receita Federal, da Polícia Federal, da Polícia Rodoviária Federal, da Secretaria Nacional de Segurança Pública e da Secretária-geral do Ministério das Relações Exteriores. As iniciativas visando a integração e articulação das ações do programa com estados e municípios ficarão a cargo do Gabinete de Gestão Integrada de Fronteiras (GGIF), grupo que também foi instituído por meio do Decreto Presidencial n ${ }^{\circ}$ 8.903, de 16 de novembro de 2016.

No escopo do PPIF serão deflagradas as Operações Ágata para combater delitos transfronteiriços e ambientais. Completando sua $11^{\text {a }}$ edição em 2017, a Operação Ágata, sob a coordenação do Ministério da Defesa e Comando do Estado-Maior Conjunto das Forças Armadas (EMCFA), integra além das Forças Armadas, cerca de 30 agências nos níveis federal, estadual e municipal, entre Ministérios, agências reguladoras e órgãos de fiscalização, segurança e inteligência, como a Agência Brasileira de Inteligência (ABIN). ${ }^{4}$

Em 2011, foram realizadas as Operações Ágata-1, no estado do Amazonas, Ágata-2, nos estados do Rio Grande do Sul, Paraná e Santa Catarina e Ágata-3, nos estados do Mato Grosso do Sul, Mato Grosso, Rondônia, Acre e Amazonas. Na sequência, no ano de 2012, ocorreram as Operações Ágata-4, nos estados do Amapá, Pará, Roraima e Amazonas, Ágata-5, nos estados do Rio Grande do Sul, Santa Catarina, Paraná e Mato Grosso do Sul, e Ágata-6, atuando em Rondônia, Mato Grosso, Mato Grosso do Sul e Acre. No ano de 2013, foi desencadeada a Ágata-7, a mais ambiciosa, pois esta compreendeu toda a faixa de fronteira do Oiapoque (Amapá) até o Chuí (Rio Grande do Sul) (Fagundes; Rückert 2014, 869). A Operação Ágata possui tamanha magnitude e envolve um contingente bélico tão expressivo que sua realização nas fronteiras, eventualmente, enrijece as relações com os países da região, em especial com as forças armadas dos países vizinhos. Por essa razão, se faz necessária a participação do Ministério das Relações Exteriores (MRE) para as tratativas diplomáticas e alinhamentos políticos com países da região sul-americana antes, durante e depois de sua deflagração.

As Operações Ágata-7 e 8 destacaram-se das demais pelas dimensões. Foram as maiores ações militares voltadas à defesa já realizadas no Brasil, tanto em número de participantes e equipamentos, quanto em abrangência. Em uma área de atuação de 2,3 milhões de $\mathrm{km}^{2}$, mais de um quarto do território nacional, cada operação contou com cerca de 30 mil militares da Marinha, do Exército e da Aeronáutica em toda a extensão da fron- 
teira brasileira com os dez países sul-americanos, o equivalente a 16.886 quilômetros. Além desse total, participaram agentes das Polícias Federal, Rodoviária Federal e Militar, bem como profissionais de agências governamentais. Durante os 11 dias de ação das Forças Armadas na Ágata-8, foram apreendidas cerca de 40 toneladas de drogas, enquanto a Ágata-7, no ano anterior, apreendeu cerca de 19 toneladas. As operações contam ainda com ações cívico-sociais, destinadas a prover cuidados básicos de saúde em comunidades isoladas.

No plano das ações sistemáticas de segurança pública, a Operação Sentinela, coordenada pelo Ministério da Justiça, conta com a atuação das Polícias Federal, Rodoviária Federal e da Força Nacional de Segurança. Tem como objetivo a fiscalização nas áreas de fronteira do Brasil para coibir o tráfico de drogas e o contrabando (Polícia Federal 2012). ${ }^{5}$ É interessante notar que as duas operações, Sentinela e Ágata, são supridas com conhecimentos de inteligência gerados no âmbito do Sistema Brasileiro de Inteligência (Sisbin).

O terceiro componente dessa estratégia nacional de proteção das fronteiras é o Sistema Integrado de Monitoramento de Fronteiras (Sisfron), uma tecnologia que ainda está em fase de implantação, mas já permite a gestão dos territórios fronteiriços por meio do monitoramento e controle das fronteiras, o que amplia a capacidade de detecção e localização de tentativas de violação do território nacional. Ademais, por meio das funções de Comando e Controle, Comunicações, Computação, Inteligência, Vigilância e Reconhecimento (C4IVR), é fortalecida a interoperabilidade das operações multiagências, como são as operações Ágata e Sentinela.

Segurança, liberdades individuais e a construção da identidade nacional

Os vultosos investimentos nacionais destinados à execução da Estratégia Nacional de Segurança Pública nas Fronteiras (Enafron), cujas maiores expressões são as operações Sentinela e Ágata, assim como a operacionalização do Sistema Integrado de Monitoramento de Fronteiras (Sisfron) levam à constatação de que a política brasileira para as fronteiras foi destacadamente a política de defesa mais importante no Brasil na última década (Vaz; Cortinhas 2013). Ao promover a integração e articulação de ações de segurança pública da União, de inteligência, de controle aduaneiro e das Forças Armadas, o Programa de Proteção Integrada de Fronteiras (PPIF) representa mais uma valiosa conquista para as forças de proteção do país, e se converte em um instrumento para o Brasil potencializar suas estratégias de preservação da soberania, garantindo a integridade territorial.

Pela perspectiva do exercício das liberdades individuais, as ações de controle e segurança em regiões de fronteira são importantes na medida em que obstam o avanço das pressões internas, externas, manifestas 
ou potenciais, oriundas particularmente do crime organizado, e que frequentemente ameaçam e oprimem os habitantes locais. São operações que reforçam e dão fôlego, em certa medida, ao nacionalismo cívico, uma vez que suscita nos habitantes a intuição de fazer parte de uma realidade administrativa imaginada. ${ }^{6}$

Não obstante sua importância, para terem êxito, as estratégias de defesa e segurança como as operações Ágata e Sentinela devem avançar, lado a lado, com programas de desenvolvimento social. Esses programas estimulam aquelas estratégias. As estratégias de proteção fornecem guarida para os programas de promoção de melhorias. Cada política reforça e retroalimenta as razões da outra e, em ambas, se desperta para o sentido de nacionalidade por meio do qual a nação é construída. Isto porque a experiência proporcionada pelo livre exercício dos direitos fundamentais estimula no cidadão a consciência de pertencer a uma coletividade política, organizada por normas e amparada pelo Estado. A ideia de participar de uma comunidade cujas relações são protegidas por um governo soberano, por sua vez, abre espaço para o processo de construção da identidade, que é elemento associado ao conceito de nação.

Marilena Chaui, considera que o conceito de nação organiza-se por elementos que visam a criar a unidade de um povo, tais como mesma língua, mesmo território, mesma pátria. São elementos destinados a estabelecer, no sentido de tornar estável, um idem, uma identidade em relação aos indivíduos de um país. Esta identidade sustenta o que se chama de identidade nacional, produzindo um efeito de unidade a partir de consensos e lealdades que justificam um nós em oposição a um eles (Chaui, 2006). Em regiões remotas de fronteira, onde o elo abstrato entre o Estado e o indivíduo se esmaece, na medida em que a prestação material do Poder Público se torna menos efetiva e o assédio de organizações criminosas mais acentuado (são inversamente proporcionais), ganha importância a percepção de identidade para a manutenção da coesão nacional.

Parece ser razoável pensar que para se preservar a unidade pátria nos confins do território nacional é importante que o cidadão local se identifique com o ethos que caracteriza o Estado de direito do qual faz parte. Ao representar-se cognitivamente como participante de uma nação unida pelo respeito à hierarquia das normas e aos direitos fundamentais, o habitante da fronteira reconstitui internamente os vínculos subjetivos com seu país, que são naturalmente esmaecidos nesses lugares. Essa construção imaginária que identifica o cidadão com sua pátria produz para a sociedade ao menos dois efeitos benéficos imediatos. $\mathrm{O}$ primeiro é suscitar nas pessoas a sensação de desconforto diante da ideia de cometer crimes ou associar-se com este propósito, já que essa opção não se coaduna com o código de 
costumes e comportamentos, valores e crenças estampados pelo Estado de direito (ethos), e ainda é objeto de punição.

O outro benefício que se extrai do processo imaginário que suscita a constituição de laços entre habitantes das regiões de fronteira e a sua nação é o fortalecimento, entre os compatrícios, da ideia de semelhança e fraternidade. A consciência da existência de elos que unificam, mesmo que de forma tênue, os habitantes da fronteira, revigora nessas sociedades a ideia de que os seus componentes fazem parte de uma estrutura maior e supra individual: o Estado. Ao perceber que integram uma realidade mais abrangente - e talvez portadora de novas possibilidades - passam a buscar formas de relacionamento com essa novel instância, isto é, passam a interagir com órgãos e instituições que representam essa realidade ampliada que é o Estado. Passam a demandar, buscar respostas e interagir com mais ênfase e de forma mais frequente para terem efetivados os seus direitos perante o Poder Público. Essa mudança de postura, assumidamente mais ativa no relacionamento com o Estado, abre espaço para o gradual desenvolvimento da cidadania e da participação popular na gestão pública. É por essa razão que a construção da identidade nacional pode revigorar conceitos importantes em uma nação democrática, como a noção de cidadania e de nacionalidade. $\mathrm{O}$ aperfeiçoamento desses conceitos é especialmente importante em regiões de fronteiras, por excelência zonas sensíveis, pois são o local de encontro de soberanias, mas também são regiões em que diferentes expressões de poder - legítimo e ilegítimo - concorrem entre si para liderar ou escravizar pessoas.

Benedict Anderson explica que nação é uma "comunidade política imaginada" (Anderson 1989, 13), assim, nas mentes dos seus habitantes está a imagem "de uma comunhão ou de uma fraternidade" cuja permanência é conquistada por meio da construção de sentidos que aproximem os integrantes da comunidade, estabelecendo referências comuns que possam ser compartilhadas entre os habitantes de uma nação. O historiador Carlos Amarilha arremata a compreensão sobre os vínculos existentes entre identidade e nação ao explicar que "a nação tem o papel de representar todos os brasileiros como pertencentes a uma grande família nacional. Desse modo, a nação é compartilhada por todos sem discriminação, o que dá significado, importância e orgulho pertencer à mesma comunidade imaginada” (Amarilha 2006, 11). Assim, os programas de promoção de melhorias, que objetivam garantir o exercício dos direitos constitucionais em regiões de fronteira, representam não apenas uma política que visa promover o bem-estar social, mas ultrapassam este propósito e se consubstanciam em estratégias que reforçam o sentimento de identidade nacional entre os habitantes da faixa de fronteira. As políticas sociais de desenvolvimento 
nas regiões de fronteira prestam, assim, uma valiosa contribuição para a integração do país. Esse resultado é difícil de ser mensurado, mas pode ser comprovado pela eficácia de seus resultados nas comunidades fronteiriças que se tornam menos vulneráveis à força ardilosa e desagregadora do crime organizado, particularmente ativo em áreas limítrofes do território nacional (World Bank 2016).

\section{POLÍTICAS E PROJETOS FEDERAIS DE DESENVOLVIMENTO PARA A FAIXA DE FRONTEIRA}

Em relação às ações, políticas e projetos federais de desenvolvimento para a Faixa de Fronteira, o auge dessas iniciativas ocorreu em 2009, especialmente com a criação do Programa de Desenvolvimento para a Faixa de Fronteira (PDFF), concebido como alavanca para a redução das desigualdades regionais (Brasil 2009). A grande inovação dessa política refere-se à abordagem dirigida às potencialidades dos espaços sub-regionais, consideradas as diretrizes políticas estaduais, municipais e das sociedades locais. Com base nas características de cada sub-região, foram definidas estratégias para o desenvolvimento de Arranjos Produtivos Locais (APL), ${ }^{7}$ que são aglomerações de empresas, localizadas em um mesmo território, que apresentam especialização produtiva e mantêm vínculos de articulação, interação, cooperação e aprendizagem entre si e com outros atores locais, tais como: governo, associações empresariais, instituições de crédito, ensino e pesquisa. Um Grupo de Trabalho Interministerial de Programas de Desenvolvimento Regional (GTI-PDR), congregando 23 ministérios e secretarias especiais, e coordenado pelo Ministério da Integração Nacional, foi instituído com o objetivo de articular a ação do governo federal para a dinamização econômica e a infraestrutura social, criando condições favoráveis à instituição dos APLs.

Apesar de ter sido concebido de forma detalhada, a partir de diagnósticos socioeconômicos realizados nas regiões de fronteira, e se valendo do moderno conceito de arranjos e sistemas produtivos locais, o PDFF até o momento (2017) não produziu os resultados que almejava. A formulação das estratégias de desenvolvimento a partir do potencial das regiões (vantagens comparativas) representa uma abordagem inovadora, mas para apresentar impactos tangíveis o programa exige um período de maturação, que ultrapassa os quatro anos de mandato presidencial. Por ser um programa de governo (transitório) e não uma política de Estado (perene), está sujeito à descontinuidade. Outra dificuldade é o fato de requerer um esforço institucional conjunto e alinhado de vários ministérios para sua plena execução, o que demanda forte coordenação e fôlego institucional 
para levar adiante um projeto de longo prazo como esse. Em Cáceres, um de seus locais de implantação, atualmente o PDFF perdeu vigor. Nessa cidade mato-grossense de fronteira as políticas de promoção do desenvolvimento por meio da cooperação interinstitucional continuam existindo, mas sofrem com o rigoroso contingenciamento de recursos imposto pelas esferas de governo.

Hoje, em Mato Grosso, apenas as políticas de defesa e segurança continuam sendo executadas nas fronteiras, mas o que se observa é que mesmo essas políticas estão esvaziadas de recursos e são impulsionadas com muito esforço no curso das ações ordinárias de monitoramento da fronteira. São executadas, sobretudo, pelo Exército Brasileiro (EB) na esfera federal e pelo Grupo Especial de Fronteira (Gefron) no âmbito estadual (Meneses 2010).

\section{ESCALA LOCAL: AS INICIATIVAS GOVERNAMENTAIS DE MATO GROSSO}

A linha limítrofe entre o Brasil e a Bolívia, com extensão total aproximada de $3.420 \mathrm{~km}$, é resultado de vários acordos diplomáticos que ocorreram entre a segunda metade do século XIX e meados do século XX. A constituição histórica da fronteira foi marcada pelo isolamento dos centros políticos dos respectivos países. Esse distanciamento, associado à falta de infraestrutura, prejudicou a organização da região e comprometeu a implementação de atividades comerciais que proporcionassem a inclusão de parcelas menos favorecidas da população ao mercado formal. Esse legado persiste, e ainda hoje a faixa de fronteira boliviana em Mato Grosso, com $730 \mathrm{~km}$ de extensão, experimenta um relativo isolamento, que a coloca à margem das políticas centrais de desenvolvimento (Assembleia Legislativa de Mato Grosso 2016).

Na fronteira Brasil - Bolívia em Mato Grosso, a baixa densidade demográfica, a vasta diversidade geográfica, as dificuldades de deslocamento e comunicação são aspectos que impõem maior complexidade ao processo de formulação de soluções para as questões relacionadas ao desenvolvimento. Por outro lado, a fiscalização estatal insuficiente torna a zona de fronteira vulnerável à proliferação de crimes transnacionais, especialmente aqueles relacionados ao contrabando, descaminho e tráfico de drogas e armas.

Verifica-se, dessa forma, um ciclo nocivo. O baixo desenvolvimento local fortalece as redes ilegais que tradicionalmente operam na região, que passam a engrossar suas fileiras com mão de obra que não encontra empregos e oportunidades no mercado formal. Aumentam, portanto, as atividades ilegais e a violência nas regiões de fronteira, o que faz acender o sinal 
vermelho nos monitores de acompanhamento dos órgãos de segurança e controle em Brasília. ${ }^{8} \mathrm{O}$ reconhecimento de altos índices de criminalidade e o clamor público, que alguns episódios de criminalidade eventualmente suscitam, levam o Poder Público a conceber novas políticas de repressão e enfrentamento que mitigam, apenas temporariamente, a grave situação de insegurança. Portanto, essas ações de enfrentamento ao crime embora legítimas e imprescindíveis, quando não são acompanhadas de programas destinados a reduzir pobreza, tornam-se frágeis e incapazes de manter seus resultados pacificadores a longo prazo.

Há quatorze anos, o governo do estado do Mato Grosso decidiu combater a criminalidade nas fronteiras integrando as forças estaduais de segurança pública através do Grupo Especial de Fronteira (Gefron). ${ }^{9}$ Essa iniciativa é reputada por analistas de segurança pública como uma resposta eficaz do Estado ao desafio da insegurança na região de fronteira. O desempenho do Gefron pode ser mensurado a partir dos indicadores eficácia e competência, propostos pelo Ministério da Justiça. A eficácia refere-se à situação final que foi desejada pela formalização de metas. Competência diz respeito à proficiência, ou seja, a forma com que se trabalhou com os recursos (Brasil 2016, 45). O desempenho do Gefron, à luz dos indicadores de eficiência e competência, revela uma performance satisfatória, isto é, a relação entre o que a unidade de patrulhamento recebeu (recursos financeiros, técnicos e tecnológicos) e o que produziu com estes elementos demonstra bom funcionamento. Apenas entre janeiro e julho de 2014 o Gefron apreendeu quase meia tonelada de cocaína e 52 veículos objeto de roubo, e impediu ações de contrabando, perfazendo um total de $\mathrm{R} \$ 105.000,00$ (Brasil 2016, 104).

O Grupo conta com um contingente de cerca de 100 profissionais, que, apesar de serem poucos diante da dimensão do desafio de patrulhar a fronteira em Mato Grosso, são bem treinados e contam com aparatos técnicos adequados ao terreno (Brasil 2016, 91). O Gefroné composto em sua maioria por integrantes da Polícia Militar, mas também fazem parte da unidade quadros a Polícia Judiciária Civil, Corpo de Bombeiros Militar e Secretaria de Estado de Fazenda, e atuam com apoio dos (e em apoio aos) órgãos federais de segurança e fiscalização. A missão institucional do Gefron é: “[ [...] Desencadear, na região, operações sistemáticas de prevenção e repressão ao: a) tráfico de drogas; b) contrabando e descaminho de bens e valores; c) roubo e furto de veículos; d) invasão de propriedades" (Mato Grosso 2016).

O Gefron conta com pequenos centros operacionais, chamadas de Bases Fixas Operacionais, estabelecidos nas localidades de Lagoa Verde ou Avião Caído (BR-070), Vila Cardoso (estrada vicinal que liga a MT 265 à BR 174) e Vila Matão (estrada vicinal que liga a MT 265 ao município de 
Pontes e Lacerda). Os policiais do Gefron são responsáveis por exercer o policiamento de $460 \mathrm{~km}$, correspondentes à linha seca central da fronteira entre o Brasil e a Bolívia, e $290 \mathrm{~km}$, distribuídos nas duas extremidades da linha divisória, que são delimitados por corpos d'água. Um dos principais focos da atuação do Gefroné a fiscalização das estradas no interior de fazendas, denominadas cabriteiras. As cabriteiras são estradas construídas clandestinamente ao longo de quase oitocentos quilômetros de fronteira, e que tem como objetivo promover o escoamento por terra de produtos de origem delituosa (Mato Grosso 2016).

Segundo Rebeca Steiman, em O Mapa da droga, um estudo ainda muito valioso para a análise sobre as rotas do tráfico no Brasil, o entorpecente boliviano tem, principalmente, quatro possibilidades de entrada em território brasileiro: 1) a droga parte de Guayaramerín, no lado boliviano, em direção a Porto Velho (RO), passando por Guajará-Mirim e Abunã; 2) a droga tem origem em San Joaquín, na Bolívia, entra em Costa Marques por estrada e segue para Cacoal, ambos município de Rondônia; 3 ) o entorpecente ingressa no Brasil através de Cáceres, em Mato Grosso, em direção à capital Cuiabá e segue para Goiânia e Brasília, passando antes por Barra do Garças; ${ }^{10}$ e 4) de Puerto Suarez, na Bolívia, a droga alcança Campo Grande (MS) via Corumbá e Ladário (MS). Daí em diante, pode entrar em São Paulo ou por Andradina, passando por Três Lagoas (MS) ou por Presidente Epitácio, São José do Rio Preto, Bauru, etc. Mato Grosso, especificamente a centenária cidade de Cáceres, representa um dos principais hubs, ou pontos de conexão para a transferência de carregamentos de narcóticos para o destino pretendido, isto é, o eixo Rio-São Paulo-exterior.

Outra ameaça gravíssima que começa a se tornar evidente na fronteira Brasil - Bolívia em Mato Grosso é o tráfico de armas. O Relatório da CPI do Tráfico de Armas (CPI do Tráfico das Armas 2006), elenca as principais rotas utilizadas pelos criminosos através de cinco vias: 1) a fronteira da região norte; 2) a fronteira com o Paraguai; 3) a fronteira com a Argentina; 4) as fronteiras com o Peru e Bolívia; e 5) os portos e aeroportos.

Para Naiane Inez Cossul, “[...] os ilícitos transnacionais são complementares, isso porque quem trafica armas pode facilmente expandir sua gama de produtos para traficar drogas, e vice-versa ou ainda como moeda de troca” (Cossul 2015, 84). Essa observação encontra respaldo nas conclusões da CPI do Tráfico de Armas, que pontua: "os crimes de tráfico de armas e de tráfico de drogas são complementares, se apoiam mutuamente, e muitas vezes ocorre a troca de armas por drogas na fronteira" (CPI do Tráfico das Armas 2006, 48-49). Moisés Naím também compartilha esse entendimento ao afirmar que "à medida que o negócio ilícito de armas se constrói e se modifica, ele se mistura a outros comércios ilegais” (Naín 
2006, 44). Há evidências de que isso que esteja ocorrendo na fronteira em Mato Grosso. Os ilícitos transnacionais, pautados nas novas ameaças, cada vez mais se entrelaçam e se difundem na região fronteiriça. Isso se deve à complementariedade entre oferta e demanda de produtos e serviços ilegais (Naín, 2006).

Já no campo das estratégias de aproveitamento das potencialidades regionais da fronteira em Mato Grosso, o mais arrojado projeto de desenvolvimento na atualidade é a implantação da Zona de Processamento de Exportação (ZPE), em Cáceres. Indústrias que se instalarem na ZPE em Cáceres terão acesso a tratamentos tributário, cambial e administrativo específicos, e, assim, serão mais competitivas na produção de bens para comercialização no exterior. Este é o atrativo para os investimentos privados na $Z$ PE-Cáceres, isto é, um regime aduaneiro especial. Há grande expectativa de que a ZPE-Cáceres se torne uma realidade ainda na atual administração de Mato Grosso, fomentando a difusão tecnológica, a geração de empregos e o desenvolvimento econômico e social.

Outro fator que contribui na atração de empresas para o interior da Zona de Processamento de Exportações de Cáceres é o Rio Paraguai, que margeia a cidade fronteiriça. Por ser largo e apresentar baixa declividade, o Rio Paraguai, com um trajeto de cerca de $2.621 \mathrm{~km}$ e banhando quatro países da América do Sul, tem condições geomorfológicas propícias para o escoamento fluvial de grãos e produtos manufaturados. Essa é uma significativa vantagem competitiva da região de Cáceres em relação a outras ZPEs no Brasil, que também buscam atrair investidores para o interior de seus parques industriais (Macedo 2016). Trata-se, portanto, de uma grande novidade na região de fronteira em Mato Grosso, um grande projeto capaz de colocar a população fronteiriça no caminho do desenvolvimento e contribuir para a construção de uma sociedade mais livre e próspera.

\section{CONCLUSÕES}

Na fronteira Brasil - Bolívia em Mato Grosso a comunicação entre os países é uma prática cotidiana. A movimentação transnacional de cidadãos, a comercialização de bens e serviços, e o intercâmbio cultural fazem parte da vida na região. Essa rotina pode significar um fator de desenvolvimento e ajudar no progresso e bem-estar das populações envolvidas. Mas para que essa convivência seja promissora, as políticas destinadas a garantir o controle e a segurança pública devem caminhar lado a lado com as estratégias de desenvolvimento social e econômico. A implementação de políticas baseadas na valorização de potencialidades locais em regiões de fronteira não somente resulta na melhoria das condições de vida do habitante local, 
mas contribui para o desenvolvimento do sentimento cívico e reduz sua exposição às ameaças relacionadas à criminalidade transfronteiriça. Isto porque a pessoa inserida no mercado de trabalho formal tem melhores condições de exercer livremente seus direitos individuais e se torna menos vulnerável ao assédio do crime organizado que atua nas fronteiras, e que se materializa especialmente no cooptação para o tráfico de drogas, de pessoas, de armas, no contrabando e na lavagem de dinheiro.

Tendo em vista a natureza multifacetada que caracteriza a realidade na fronteira Brasil - Bolívia em Mato Grosso, é apropriado que a análise de seus aspectos seja realizada de maneira multidimensional, correlacionando os problemas de segurança na fronteira às condições socioeconômicas e oportunidades do lugar. Dessa forma, as estratégias de defesa e segurança devem avançar, lado a lado, com programas de desenvolvimento. Uma estratégia reforça as razões da outra. Em ambas, desperta-se para a ideia de cidadania e se constrói em mentes e corações o conceito de Nação, tão fundamental para se aprofundar a integridade nacional em regiões de fronteira. Defendido e seguro, o Brasil poderá opor resistência às ações adversas, internas e externas, quando for necessário. Desenvolvido, criará condições para sua população fazer escolhas de forma livre e consciente, sem ter que se curvar diante da tirania do crime organizado. O ciclo combinado e contínuo de desenvolvimento e segurança na fronteira, que se reforça e se aperfeiçoa mutuamente a cada ciclo, é o melhor caminho para se alcançar de forma duradoura a justiça e a paz social.

\section{REFERÊNCIAS}

ABIEC - Associação Brasileira das Indústrias Exportadoras de Carne. 2016. Perfil da Pecuária no Brasil - Relatório Anual 2016. Disponível em: < http://www.abiec. com.br/>. Acesso em: 11 out. 2016.

Amarilha, Carlos Magno Mieres. 2006. Os Intelectuais e o Poder: História, Divisionismo e Identidade em Mato Grosso do Sul. Dissertação de Mestrado em História, Universidade Federal da Grande Dourados, Dourados.

Anderson, Benedict R. 1989. Nação e Consciência Nacional. São Paulo: Ática.

1991. Imagined Communities: Reflections on the Origin and Spread of Nationalism. 2. ed. [S.1.]: Verso.

Assembleia Legislativa de Mato Grosso. 2016. A Fronteira Brasil-Bolívia no Mato Grosso - 2016. Cuiabá: ALMT. 
Beltrame, José Mariano. 2010. Veja Acompanha Terror no Rio. Entrevista. Revista Veja, São Paulo, 31 nov. 2010. Disponível em: <http://www.dpf.gov.br/servicos/ viagens-ao-exterior/postos-de-fiscalizacao-do-trafego-internacional-terrestre $>$. Acesso em: 1 jun. 2016.

Brasil. 2009. Faixa de Fronteira. Programa de Promoção do Desenvolvimento da Faixa de Fronteira - PDFF. Brasília: SPR - Secretaria de Programas Regionais/ Ministério de Integração Nacional.

2011. Decreto $n^{\circ}$ 7496, de 08 de junho de 2011 . Disponível em: $<$ http:// www2.planalto.gov.br/acervo/legislacao>. Acesso em: 16 jun. 2017.

2012. Ministério da Defesa. Operações Interagências. MD33-M-12. Brasília: Ministério da Defesa .

2016a. Metodologias de Funcionamento e Estruturação de Unidades Especializadas de Fronteira: Estratégia Nacional de Segurança Pública nas Fronteiras (ENAFRON). Organizado por Alex Jorge et al. Brasília: Ministério da Justiça e Cidadania, Secretaria Nacional de Segurança Pública.

2016b. Lei Complementar $n^{\circ} 136$, de 25 de agosto de 2010. Disponível em: <http://www2.planalto.gov.br/acervo/legislacao>. Acesso em: 16 jun. 2017.

Cassol, Naiane Inez 2015. Tráfico Internacional de Armas na Fronteira Brasil/ Bolívia: Dinâmicas de Insegurança Regional e o Posicionamento Brasileiro. Dissertação de Mestrado, Universidade Federal de Santa Catarina, Florianópolis.

Castro, Iná Elias de. 1995. O Problema da Escala. In: Castro Iná Elias de; Gomes, Paulo César da; Corrêa, Roberto Lobato. (Org.). Geografia: Conceitos e Temas. Rio de Janeiro: Bertrand Brasil.

Chaui, Marilena. 2006. Brasil: Mito Fundador e Sociedade Autoritária. São Paulo: Fundação Perseu Abramo.

Couto e Silva, Golbery 1981. Conjuntura Política Nacional: O Poder Executivo E Geopolítica do Brasil. Rio de Janeiro: José Olympio.

CPI do Tráfico de Armas. 2006. Relatório da Comissão Parlamentar de Inquérito Destinada a Investigar as Organizações Criminosas do Tráfico de Armas. Projeto de Resolução nº 189 de 2005. Brasília: Câmara dos Deputados.

Da Costa, Eduardo José Monteiro. 2010. Arranjos Produtivos, Locais, Políticas Públicas e Desenvolvimento Regional. IDESP - Instituto de Desenvolvimento Econômico, Social e Ambiental do Pará. Brasília: Mais Gráfica Editora. 
Dorfman, Adriana. 2013. A Condição Fronteiriça diante da Securitização das Fronteiras do Brasil. In: Nascimento, D. M.; Porto, J. R. Fronteiras em Perspectiva Comparada e Temas de Defesa da Amazônia. Belém: Ed. UFPA.

Fagundes, Flávia Carolina de Resende; Rückert, Aldomar Arnaldo. 2014. Entendendo a Segurança Fronteiriça, uma Abordagem Multiescalar: o Caso da Tríplice Fronteira Brasil-Argentina-Paraguai. Anais do $1^{\circ}$ CONGEO. Pontifícia Universidade Católica do Rio de Janeiro. Rio de Janeiro: Ed. Gávea.

Força Aérea Brasileira. 2013. Operação Ágata: Plano Estratégico de Fronteira. Brasília: FAB. Disponível em: <http://www.fab.mil.br/portal/>. Acesso em: 2 dez. 2016.

Macedo, Daniel Almeida de. 2016. Cáceres e o Exterior. Jornal A Gazeta, 11 de abril de 2016. Disponível em: <https://www.gazetadigital.com.br/conteudo>. Acesso em: 10 jun. 2016.

Mato Grosso. Secretaria de Estado de Justiça e Segurança Pública. 2017. Missão do GEFRON. Disponível em: <http://www.seguranca.mt.gov.br/GEFRON>. Acesso em: 6 jun. 2017.

Meneses, Paulo Hernandes Rodrigues 2010. A Atuação do GEFRON na Fiscalização do Tráfico de Drogas na Fronteira de Mato Grosso. Revista Homens do Mato, 6, 106-121, jan./jun.

Ministério da Defesa. 2017. Exercícios e Operações Militares. Disponível em: $<$ http://www.defesa.gov.br/exercicios-e-operacoes>. Acesso em: 15 jun. 2017.

Naín, Moises 2006. Ilícito - o Ataque da Pirataria, da Lavagem de Dinheiro e do Tráfico à Economia Global. Rio de Janeiro: Jorge Zahar.

Neves, Alex Jorge das et al. 2016. Segurança Pública nas Fronteiras, Sumário Executivo: Estratégia Nacional de Segurança Pública nas Fronteiras (ENAFRON). Brasília: Ministério da Justiça e Cidadania/Ed. Secretaria Nacional de Segurança Pública.

Polícia Federal. 2012. PF Apresenta Balanço de um Ano da Operação Sentinela. Brasília: Departamento da Polícia Federal, 2012. Disponível em: <http://www.dpf.gov.br/ agencia/noticias/2012/junho/pf-apresenta-balanco-de-um-ano-da-operacaosentinela >. Acesso em: 14 nov. 2013.

Racine, Jean Baptiste; Raffestin, Claude; Ruffy, Victor. 1993. Escala e Ação: Contribuições para uma Interpretação do Mecanismo de Escala na Prática da Geografia. Revista Brasileira de Geografia, Rio de Janeiro, 45, 1, 123-135, jan. /mar. 
Raza, Salvador. 2014. Proposição de um Sistema de Segurança de Fronteiras Brasileiras: um Esforço para Transformar o Desenho da Força. In: Nasser, Reginaldo Mattar; Moraes, Rodrigo Fracalossi de. O Brasil e a Segurança no seu Entorno Estratégico. Brasília: IPEA.

Renan, Ernst. 1997. O que é uma Nação? Tradução de Gabriel Titan Jr. Revista de Ciências Sociais, São Paulo, 4, 1.

Rückert, Aldomar. 2013. Políticas Territoriais, Crise Europeia e Fronteiras: Perspectivas Comparadas entre a União Européia e o Brasil. In: Nascimento, Durbens Martins; Porto, Jadson Rebelo. Fronteiras em Perspectiva Comparada e Temas de Defesa da Amazônia. Belém: Ed. UFPA.

Steiman, Rebeca. 1995. O Mapa da Droga. Monografia, Departamento de Geografia, Universidade Federal do Rio de Janeiro, Rio de Janeiro.

Turner, Frederick Jackson. 1999. The Significance of the Frontier in American History. Rereading Frederick Turner. New Heaven; Londres: Yale University Press.

Vaz, Alcides. Costa.; Cortinhas, Juliano. 2013. Las Políticas Brasileñas de Defensa y Seguridad en 2012-2013: una Trayectoria Tortuosa y Paradójica. In: Mathieu, Hans;Guarnizo, Catalina Niño. (Ed.). Anuario 2013 de la Seguridad Regional en la América Latina y el Caribe. Bogotá: Friedrich Ebert Stiftung.

Wegner, Robert. 2000. A Conquista do Oeste. A Fronteira na Obra de Sérgio Buarque de Holanda. Belo Horizonte: Ed. UFMG.

World Bank. 2016. Stop the Violence in Latin America: a Look at Prevention from Cradle to Adulthood. Organized by Laura Chioda. Washington: WB. 


\section{NOTAS}

1. Zona-tampão: o termo é aplicado às zonas estratégicas onde o Estado central restringe ou interdita o acesso à faixa e à zona de fronteira, criando parques naturais nacionais, áreas protegidas ou áreas de reserva, como é o caso das terras indígenas (Brasil 2009).

2. Benedict Anderson definiu nação como "uma comunidade política imaginada, porém limitada por excelência” (Anderson 1991, 224).

3. Os dados da cadeia bovina foram calculados pela Agroconsul, a partir de uma metodologia adotada e desenvolvida em 2010 pelo Pensa USP - Centro de Conhecimento em Agronegócios.

4. Disponível em: http://www.defesa.gov.br/exercicios-e-operacoes/ operacoes-conjuntas-1/operacao-agata. Acesso em 25.05.2017.

5. Disponível em: <http://www.douradosagora.com.br/noticias/policial/ dof-intensifica-fiscalizacao-para-coibir-contrabando-de-pneus $>$. Acesso em: 25 mai. 2017.

6. Sobre a necessidade de se manter vivo o conceito de nacionalidade cívica, Joseph Ernest Renan, historiador francês em conferência realizada na Universidade Sorbonne, em 11 de março de 1882, definiu a nação como um "referendo diário" ou um "plebiscito diário", isto é, "dependente da vontade de seu povo para continuarem a viver juntos" (Renan 1997).

7. Nos últimos anos os arranjos produtivos locais (APLs) vêm se constituindo como um importante instrumento de política econômica, considerado pelo Ministério da Integração Nacional como um dos mais importantes instrumentos de geração de emprego e renda para a estratégia de redução das históricas desigualdades regionais brasileiras. Ver Da Costa (2010).

8. Em referência, especialmente, às atividades de monitoramento realizadas pela Senasp (Secretaria Nacional de Segurança Pública). A Senasp efetua, por meio de informações enviadas regularmente pelas Secretarias Estaduais de Segurança Pública dos Estados, o acompanhamento da Política Nacional de Segurança Pública e dos Programas Federais de Prevenção Social e Controle da Violência e Criminalidade, assessorando o Ministro de Estado na definição, implementação e acompanhamento da Política Nacional de Segurança Pública e dos Programas Federais de Prevenção Social e Controle da Violência e Criminalidade. Ver: Decreto ${ }^{\circ}$ 6.061, de 15 de março de 2007, Anexo I.

9. O Gefron - Grupo Especial de Fronteira, (Gefron) foi criado no Estado de Mato Grosso no dia de 13 de março de 2002, através do Decreto Estadual $n^{\circ} 3.994$.

10. Essa rota se bifurca em uma ramificação com destino a São Paulo, passando por Uberlândia (MG) e Ribeirão Preto (SP). Desse ponto parte para o mercado internacional. 
FRONTEIRA BRASIL - BOLÍVIA EM MATO GROSSO:

SEGURANÇA PÚBLICA, DESENVOLVIMENTO SOCIAL E A CONSTRUÇÃO DA IDENTIDADE NACIONAL

\section{RESUMO}

O presente texto aborda as políticas de segurança pública e defesa nacional na fronteira Brasil - Bolívia em Mato Grosso, correlacionando-as com as políticas de desenvolvimento vigentes (ou ausentes) na região e destaca sua importância para a construção do sentimento de identidade nacional. O texto corrobora o entendimento segundo o qual a estratégia nacional de proteção das fronteiras é inseparável da estratégia de desenvolvimento, e que a "via inversa" da valorização das potencialidades regionais tem o condão de reduzir a insegurança das populações locais diante da ameaça que representa o crime organizado.

Palavras-chave: Fronteira; Desenvolvimento; Segurança Pública; Identidade Nacional.

\section{SUMMARY}

The present text deals with the policies of public security and national defense at Brazil - Bolivia border in the state of Mato Grosso, correlating them with the current (or absence) development policies in the region and highlights its importance for the construction of the sense of national identity. The text supports the view that national strategy focused on the protection of borders is inseparable from developmental strategies and that the "reverse path" of enhancing regional potentials brings the possibility to reduce insecurity of local populations facing the threats posed by organized crime.

Keywords: Frontier, development, public security and national identity. 